\title{
EDITORIAL
}

\section{The fever of stem cells has taken possession of us!}

Leukemia (2006) 20, 1474. doi:10.1038/sj.leu.2404311

To the invitees of the New Stem Cell Spotlight

We are both very enthusiastic about all the new developments that are on the market or will be. Therefore, we are very happy to invite you to a new Spotlight series, more precisely, the New Stem Cell Spotlight. Remains now to do the job!

Spotlight articles are reviews heralded by one or several individuals who are recognized experts in their fields and here, in this case, experts of stem cell research. These Spotlight articles should be commanding papers. The length can be variable. In general, we try to start the series with three or four papers at the same time. But as a rule, the papers should be published as they come. And therefore, the Spotlights can spread over a year or so depending on how many new authors we recruit. Of course, these invited reviews will be refereed but of course with special attention to the way in which we will choose the referees. This is possible because of the reasonable number of Spotlight articles that we expect in the future.

The topics related to Stem Cells impact on many facets. To start with, we should concentrate on the hemopoietic stem cells, and even within this field, there are many interesting facets. Some of us are interested in normal or/and malignant stem cells, and some are more focused on hematopoietic differentiation of embryonic stem cells. A special attention will be given to regulation of stem cell trafficking and the interaction within the bone marrow with the hematopoietic niches.

The work of our invitees is very well known to us and deserves to be publicized with all the might we can muster through the channels of Nature in order that it reaches an important segment of the scientific community.

We encourage invitees to select a topic of their review that will reflect the best of their major scientific interest and personal contribution to the field and most important we ask them to give some personal thoughts and insights to the topic. Thus, in each paper, we will reserve a paragraph for wide speculations...if desired!

Leukemia, as you know, has an impeccable record of publishing top scientific papers in the area of Hematology and Oncology. It is distributed by Nature Publishing Group and is accessible on-line.

We shall start this new Spotlight series with a review from Dr Ratajczak entitled Membrane-derived microvesicles (MV): important and underappreciated mediators of cell to cell communication.

Sincerely yours,

MZ Ratajczak and NM-B Killmann Stem Cell Biology Program, James Graham Brown Cancer Center, University of Louisville, Louisville, KY, USA E-mail:mzrata01@louisville.edu 